\title{
The undergraduate optics course at Millersville University
}

\section{Tariq Gilani, Natalia Dushkina}

Tariq H. Gilani, Natalia M. Dushkina, "The undergraduate optics course at Millersville University," Proc. SPIE 9666, 11th Education and Training in Optics and Photonics Conference, 966618 (5 June 2009); doi: $10.1117 / 12.2208036$

SPIE Event: Eleventh International Topical Meeting on Education and Training in Optics and Photonics, 2009, St. Asaph, United Kingdom 


\title{
The Undergraduate Optics Course at Millersville University
}

\author{
Tariq H. Gilani and Natalia M. Dushkina \\ Department of Physics, Millersville University, P.O. Box 1002, Millersville, PA 17551-0302 \\ Tel: (717) 872-3291; (717)872-3424; Fax: (717) 872-3985, \\ E-mail: tariq.gilani@millersville.edu ; Natalia.Dushkina@millersville.edu
}

\begin{abstract}
For many years, there was no stand alone course in optics at Millersville University (MU). In the fall of 2007, the Physics Department offered for the first time PHYS 331: Fundamentals in Optics, a discovery based lab course in geometrical, physical and modern optics. This 300-level, 2 credits course consists of four contact hours per week including one-hour lecture and three hours laboratory. This course is required for BS in physics majors, but is open also to other science majors, who have the appropriate background and have met the prerequisites. This course deals with fundamental optics and optical techniques in greater depth so that the student is abreast of the activities in the forefront of the field. The goal of the course is to provide hands-on experience and in-depth preparation of our students for graduate programs in optics or as a workforce for new emerging high-tech local industries. Students learn applied optics through sequence of discovery based laboratory experiments chosen from a broad range of topics in optics and lasers, as the emphasis is on geometrical optics, geometrical aberrations in optical systems, wave optics, microscopy, spectroscopy, polarization, birefringence, laser generation, laser properties and applications, and optical standards. The peer-guided but open-ended approach provides excellent practice for the academic model of science research. Solving problems is embedded in the laboratory part as an introduction to or a conclusion of the experiment performed during the lab period. The homework problems are carefully chosen to reflect the most important relations from the covered material. Important part of the student learning strategy is the individual work on a final mini project which is presented in the class and is included in the final grading. This new course also impacted the department's undergraduate research and training programs. Some of the individual projects were extended to senior research projects in optics as part of the senior research and seminar courses, PHYS 492 and PHYS 498, which are required for graduation for all physics majors. The optics course also provides basic resources for both research and training in the classical and modern optics of high-school students and K-12 teachers. The successful implementation of the optics course was secured by a budget of about $\$ 60,000$.
\end{abstract}

Keywords: optics, laboratory course, optics education

\section{INTRODUCTION}

Optics, the study and manipulation of visible light, has always been an important sub-discipline in physics, and clearly, it contributes to the most important technologies of the $21^{\text {st }}$ century. Optical devices and laser applications are already an inherent part of our daily life. In recent decades, the use of optics has transcended the traditional devices such as cameras, microscopes, and binoculars and has merged with atomic physics and nanotechnology. The development of the laser and the use of optical cable for communication initiated a new technological revolution. The euphoria for internet connectivity and the huge amount of information upload daily via the internet impose rapidly rising demands for higher bandwidth and faster speed which drives the incessant growth and development of fiber optic communications [1]. Every single student in our classes has a cell phone and a CD player, but few know what an optical fiber is and how a laser works.

Understanding the nature of light, its propagation and interaction with matter is essential to physics and hands-on experiences greatly enhance that understanding. For more than 20 years, there was no single course at MU dedicated to optics at any level, although optics was woven into some courses and laboratories such algebra 
and calculus based PHYS 132 or 232. Following the recommendation in the five-year department review report, the Physics Department decided to expand its undergraduate physics curriculum and to increase its expertise in this important sub-discipline. The first step that the department took in this direction was to hire two specialists in experimental optics and solid state physics, who are also the authors of this paper. This immediately resulted in an increased number of undergraduate research projects in optics such as measuring the speed of light in water, observation of surface plasmon resonance effect in thin silver and gold films, applications of laser pointers in the secondary physics education, measuring the light momentum, holography in thin films of silver halogenide and holographic recording in lithium-neobate crystals [2]. After careful study of the experience of the optics programs at New Jersey Institute of Technology (NJIT) [3, 4], North Dakota State University (NDSU) [5] and Indiana University of Pennsylvania (IUP) [6], the authors of the paper developed a new rigorous labbased optics course. This was offered for the first time at MU in fall 2007. Since then, the course is offered every fall semester. A budget of about $\$ 60,000$ provided by the Dean of the School of Mathematics and Science secured the state-of-the-art laboratory equipment for the course. The equipment is also being used by physics students and faculty for their research in the field of optics, as well as to evoke an interest in top high school students in optics and science carriers. With an addition of another advanced optics course in future, the Department will be able to offer a new option in BA physics with optics. The optics course provides the basic resources for both research and training in modern optics. It promotes learning, teaching and training of students, faculty and K-12 teachers.

The purpose of this paper is to report on the progress of the new course in optics that is currently offered every fall at MU. The course goals, objectives, contents, equipment, assessments and progress are also discussed.

\section{1 Who are we?}

Millersville University (MU) is one of the 14 universities within the Pennsylvania State System for Higher Education (PSSHE). Founded in service to a rural nineteenth century Lancaster Pennsylvania, twenty-first century Millersville University is a vibrant public liberal arts university in a vital economic region. MU promotes intellectual development through a comprehensive range of meritorious baccalaureate and master programs offered to more than seven thousands undergraduates and about a thousand graduate students. Millersville has earned its place among US News \& World Report's top public universities in the North and is recognized for its academic excellence in Martin Nemko's book, "How to Get an Ivy League Education at a State University." [7]

All resources, time, funding, and energy of the MU Physics Department are focused on doing one thing extremely well: Undergraduate Physics. We challenge thoughtful students, providing the opportunity and incentive for all to achieve their fullest. The Department offers high-quality four-year undergraduate degrees of BS and BA in Physics (option in computer science, meteorology, nanotechnology, philosophy and polymer science), and BS in Education, as well as two co-operative engineering programs. The first is a 3/2 Program three years at MU and two at Pennsylvania State University (PSU) or University of Southern California, after which students get two degrees, BA in Physics and BS in Engineering. The second co-operative program is a 4/2 Program with PSU which offers BS in Physics and MS in engineering degrees. The BA with Nanotechnology option is also a co-operative program with Penn State. A student takes the basic physics courses of a B.A. degree at Millersville, and after spending a semester at the Penn State Nanofabrication Facility learning the specialized techniques of nanotechnology, receives a BA degree from Millersville in Physics with a Nanotechnology Option. The department of physics is one of seven departments in the School of Science and Mathematics and consists of seven full-time and one permanent part-time faculty. At any time we have about 60 physics majors. On the average, nine students graduate every year from our department. We have low student/faculty ratio (15/1) and all labs are taught by Ph.D. faculty using hands-on experiments and not simulations. Many upper level elective courses in Physics have 5-12 students. Because we do not have a graduate degree program, advanced projects are integrated into the curriculum and are focused on the undergraduate student.

Millersville is conveniently located in the heart of Susquehanna Valley, almost equally distant from Philadelphia, Baltimore and Washington DC, and at about three hours drive from New Jersey and New York, an area of abundant advanced research centers and high-tech industries providing more opportunities for employment and graduate studies while keeping vital connections to the local community. The driving distances to Pittsburg, State College and Rochester facilitate the contacts with the Northpointe Technology Center in Freeport, Penn State Technology Park and The Institute of Optics, University of Rochester. 
Millersville University has the most successful science programs of any school within the PSSHE system. The Physics Department, in particular, has generated over the last ten years many more Baccalaureate degrees than any other PSSHE University. However, we cannot be complacent. Technologies and their societal relevance change and we must adapt with them. This optics course is an important component in maintaining the currency of our programs and retaining our ascendant position within the PSSHE system.

\section{THE NEW OPTICS COURSE (PHYS 331) AT MU}

\subsection{Goals and Objectives}

The importance of optics is described in the syllabus of the course. Optics and laser systems, and their applications are an inherent part of our daily life - from classical optical systems, such as microscopes and telescopes, to CD and DVD players, cell phones, iPods, laser pointers, laser bar scanners, sophisticated devices for measurements and control, material processing systems, etc. Optics and lasers have direct implications in chemistry, biology, medicine, residential life and industry. Optics, the science of dealing with the propagation and manipulation of light, has always been an important sub-discipline in physics, and is crucial to advancement in science and technology. Understanding the nature of light, its propagation and interaction with matter is essential to constantly emerging newest technologies. Hands-on experience in optics and photonics are greatly appreciated in the modern industrial job market.

The goal of this lab-based course is to give students a detailed look at classical and modern optics, to provide hands-on experience at a rapidly growing field and in-depth preparation for graduate programs in optics, or for realizations as a workforce at high-tech industries.

The main objective of the course is to provide physics majors and other science students with hands-on experience and in-depth preparation for graduate programs in Optics, Optoelectronics, Optical Engineering, or as a workforce for new emerging high-tech local industries, via broader and deeper knowledge of basic concepts and principles of optics and optical techniques. The course introduces the basic optical systems and techniques in greater depth so that the student is abreast of the activities in the forefront of the field. Students are required to participate in a multidisciplinary project, complete a report and give a PowerPoint ${ }^{\circledR}$ presentation in class. After successful completion of this course, students will be able to:

1. Comment on basic concepts and principles of geometrical, physical and modern optics.

2. Discuss the nature of light, its propagation and interaction with matter.

3. Describe basic optical phenomena, the principles of lasers and their applications.

4. Discuss the Maxwell's electromagnetic theory of light and derive simple relations from the basic optics laws.

5. Handle and align optical elements and set-up basic optical experiments.

6. Operates optical devices and equipment.

7. Handle and align a laser cavity.

8. Measure basic parameters of laser light.

\subsection{Course description}

PHYS 331 Optics is 300-level of two credit hours and is taken by students typically in their fifth semester. This course is required for BS physics majors, but is open also to chemistry, biology, earth science, computer science and other majors, who have met the prerequisite requirements MATH 211 Calculus-II and university general physics PHYS 232 or PHYS 132. This optics course is very useful for chemistry majors since it provides basic knowledge of optics associated with the analytical part of chemistry. It is beneficial also for computer science majors, since knowledge of modern optics is essential for fiber optics communication and data storage. Microscopes and lasers are widely used also in biological experiments. The MU Biology and Chemistry Departments have a well-equipped microscopy center, including a Scanning Electron Microscope (SEM) and an Atomic Force Microscope (AFM), which is actively used by students and faculties for undergraduate research. Therefore, biology majors are encouraged to gain knowledge in optics before they handle the sophisticated instruments in this center.

The course enrollment is restricted only by prerequisites and lab equipment limitations. The initial budget ensured the equipment for four lab stations. The Department provided a large laboratory room dedicated only to 
this course. Considering three students per station, the maximum enrollment in the course at this moment is limited to 12 students.

The optics course is designed for juniors and seniors whose background is one year of university physics and two years of calculus and differential equations. To facilitate their transition to the challenges of the new course, we put some review materials on the department website. The highest priority of our optics course is creative and critical thinking, and life-long learning. This determines our teaching strategies. We emphasize concept development and qualitative and quantitative analysis. Demonstrations, thought experiments, guided class and group discussions, especially about misconceptions concerning optics, case studies, and peer-guided problem solving are part of our interactive learning strategies. Students learn and experience applied optics through sequence of open-ended laboratory experiments and multidisciplinary projects. In order to enhance interactive learning and deeper understanding of the most important concepts and phenomena of optics, the laboratory exercises are designed as hands-on use of state-of-the-art equipment. This guided but open-ended approach provides excellent practice for the academic model of science research. The lab experiments are chosen from a broad range of topics in optics and lasers, as the emphasis is on geometrical optics, wave optics, microscopy, spectroscopy, polarization, birefringence, and properties of lasers. Both, the lab and lecture portions of the course are taught by PhDs.

The optics course consists of one-hour lecture and a three-hour lab. The laboratory portion is the critical and most important part of the course, since it provides the tools and experience that students can take back to their respective disciplines and projects. The laboratory part uses the discovery based approach in which students have to investigate a hypothesis by designing and realizing the experiments, predicting relations and results, and processing the data. Therefore, no laboratory experiment write-ups are handed out, but students have access to the devices and optical kit manuals. Additional materials over the Web may also be used.

Since the new course is open to different science majors, we offer multidisciplinary projects which enable them to successfully apply optics in their respective majors. The projects are offered in the beginning of the course to provide an early start and enough time for accomplishment. The projects are determined on the base of the student's interests and background, current undergraduate research projects they are working on, prospective plans for graduate studies or eventual job placement. Some example of such projects offered are optical properties of thin semiconductor films or sculptured thin films, diffraction from thin films of self-assembled micron size polystyrene particles, image processing, fiber optics, interferometric measurements, digital holography, etc. Presentations can include theoretical background, live demonstrations, simulations, and experimental results.

\subsection{Course content}

The general physics courses encompass some concepts of electromagnetic waves and propagation of light: reflection, refraction, and total internal reflection, image formation with lenses and mirrors, fibers, dispersion, interference, diffraction, polarization, atmospheric phenomena, human eye, color mixing, shadows, eclipses. But all these basic optical phenomena are described usually in two chapters, sometimes just a paragraph for a topic with broad applications. The new optics course enriches and broadens this background with knowledge about aberrations of optical systems, microscopes and telescopes, cameras and photography, visual processing, light sources and detectors, quantum nature of light, lasers, laser applications, holography, birefringence, thin films and optical coatings, nonlinear optical phenomena, ocean optics, ultraviolet (UV) and infrared (IR) optics materials. Part of the lecture material is covered in the laboratory using just-in-time teaching method. Students from different science departments work on optics projects related to their discipline and have to make a PowerPoint ${ }^{\circledR}$ presentation to the entire class. Besides background learning on their own, this covers various topics that would not normally be included in the course.

The lecture portion of the course follows the main topics in the E. Hecht, Optics, $4^{\text {th }}$ ed., Addison Wesley, 2002. Other classical texts are also recommended to the students and are possibly in use [8]-[12]. Course material is available to students also through the university's Blackboard website. There is rich information posted on the websites of NJIT and NDSU which is also referred to the students. This, in addition, introduces our students to the facilities and curricula of these leading Optics programs.

We offer fourteen separate experiments completed in three-hour blocks. The lab portion of the course starts with an introduction to the safety standards of using optical and laser sources and systems. The basic equipment for most of the experiments is The Projects in Optics Kit of Newport Corp. This is a set of laboratory equipment 
containing all of the optics and optomechanical components needed to complete a series of experiments that provides students with basic background in optics and practical hands-on experience in laboratory techniques. The kit comes with a very well written workbook [13], which serves as the main supplement to lectures and is available to students as a source of information for the lab projects. For the last experiment, an investigation of the Helium-Neon (He-Ne) laser cavity, students are challenged to build a He-Ne laser using the state-of-the-art MICOS' He-Ne laser kit. We are aware that the lab experiments and individual projects require careful guidance to secure the successful student's performance and data interpretations. We rely on the previous experiences of the science majors with our PHYS 232 general physics course which uses the peer-reviewed discovery based approach in the physics lab.

Table 1: PHYS 331 Optics Laboratory

\begin{tabular}{|c|c|c|}
\hline & Lab projects & $\begin{array}{ll}\text { Description } \\
\end{array}$ \\
\hline 1 & $\begin{array}{l}\text { The laws of geometrical optics; } \\
\text { Introduction to optical systems } \\
\text { (handling and alignment of } \\
\text { optical elements) }\end{array}$ & $\begin{array}{l}\text { This is an introductory lab which makes the transition to the new } \\
\text { course via summarizing the student's previous experiences in optics } \\
\text { from the general courses in physics and introduces the students to more } \\
\text { complicated optical systems. Students get familiar with safety } \\
\text { standards. }\end{array}$ \\
\hline 2 & Reflection and refraction & $\begin{array}{l}\text { Laws of reflection and refraction; Prisms: Dove prism, roof prism, } \\
\text { retro-reflectors; total internal reflection; attenuated total internal } \\
\text { reflection; }\end{array}$ \\
\hline 3 & $\begin{array}{l}\text { The thin lens equations, } \\
\text { Imaging; Geometrical } \\
\text { aberrations, telescope }\end{array}$ & $\begin{array}{l}\text { Image formation, telescopes and binoculars, correction of aberrations, } \\
\text { photodetectors and computer data acquisition with Vernier } \\
\text { SoftwarelLogger Pro } 3 \text {. }\end{array}$ \\
\hline 4 & Optical systems & $\begin{array}{l}\text { Expanding laser beams, Divergence. The experiment demonstrates the } \\
\text { design of two types of laser beam expanders - the Galilean and the } \\
\text { Keplerian. Students gain experience in alignment of laser beams. }\end{array}$ \\
\hline 5 & Microscopy & $\begin{array}{l}\text { Optical microscope, magnification and resolution limits, Scanning } \\
\text { Electron Microscope (SEM), Atomic Force Microscope (AFM) }\end{array}$ \\
\hline 6 & Diffraction of circular apertures & $\begin{array}{l}\text { Fresnel and Fraunhofer diffraction. Students measure the diffraction } \\
\text { effects of circular apertures and experience how the size of the aperture } \\
\text { determines the resolving power of all optical instruments. }\end{array}$ \\
\hline 7 & $\begin{array}{l}\text { Single slit diffraction and } \\
\text { double slit interference }\end{array}$ & $\begin{array}{l}\text { Using a single "infinitely" tall slit, students witness the diffraction } \\
\text { which takes place in direction perpendicular to the small dimension } \\
\text { and investigate the interference pattern of two nearby slits, and } \\
\text { diffraction grating properties. }\end{array}$ \\
\hline 8 & The Michelson interferometer & $\begin{array}{l}\text { Students build a Michelson interferometer and use it as a means to } \\
\text { observe small displacements and refractive index changes. }\end{array}$ \\
\hline 9 & Interference of light & $\begin{array}{l}\text { Newton's rings, thin-film interference. Students will use the same } \\
\text { arrangement as in lab } 8 \text { to test optical components in monochromatic } \\
\text { light (Twyman-Green interferometer). }\end{array}$ \\
\hline 10 & Lasers and coherence & $\begin{array}{l}\text { Students examine the frequency separation between the axial modes of } \\
\text { a He-Ne laser with Michelson interferometer. }\end{array}$ \\
\hline 11 & Polarization of light & $\begin{array}{l}\text { The students use a He-Ne laser with three modes (two of the modes } \\
\text { polarized orthogonally to the third mode) to get experience in the } \\
\text { orientation and generation of polarized light, as well as mode } \\
\text { sweeping. }\end{array}$ \\
\hline 12 & Birefringence of materials & $\begin{array}{l}\text { Students become familiar with uniaxial crystals, the extraordinary } \\
\text { index of refraction and quarter-wave plates by using birefringence of a } \\
\text { material to change polarization of light; students build an optical } \\
\text { isolator and polarization rotator. }\end{array}$ \\
\hline 13 & The Abbe theory of imagining & $\begin{array}{l}\text { Students investigate the spatial frequency content of objects and how } \\
\text { they could be used to control shape and quality of image. }\end{array}$ \\
\hline 14 & He-Ne Laser Cavity & $\begin{array}{l}\text { Students use MICOS' state-of-the-art laser education kit to get familiar } \\
\text { with optical cavity (confocal cavity, near concentric cavity), to build a } \\
\text { He-Ne laser and to optimize its properties (intensity distribution, } \\
\text { divergence). }\end{array}$ \\
\hline
\end{tabular}




\section{PROGRESS}

Five students in fall of 2007 and four students in fall of 2008 have successfully completed this course. Out of the nine students, seven were physics majors, one from Chemistry, and one from Biology Departments. After graduation, one of the students from the optics class continued in a Ph.D. program that actively involves optical measurements. The following words are taken from an unsolicited letter from one of the optics alumni: "I think the background and experience I got from your [Optics] course has helped me a great deal both in undergrad analytical chemistry and now as a grad student. Again I think it was an excellent class and highly recommend it to students who have any desire to work with analytical instruments in physics or chemistry."

\subsection{Individual projects}

The following projects were completed: restoration of art holograms, interferometric thermometer, interferometric measurement of refractive index of sucrose solutions, construction of a hand-made photodetector, and longitudinal laser modes selection.

\subsection{Senior projects}

Few examples of senior research projects included in PHYS 492 and PHYS 498 are: Surface Plasmon Resonance (SPR) observation (Fig. 1), Laser pointers in high-school physics education (Fig. 2), Holography (Fig. 3), Diffraction from self-assembled structures of polystyrene microparticles, etc.

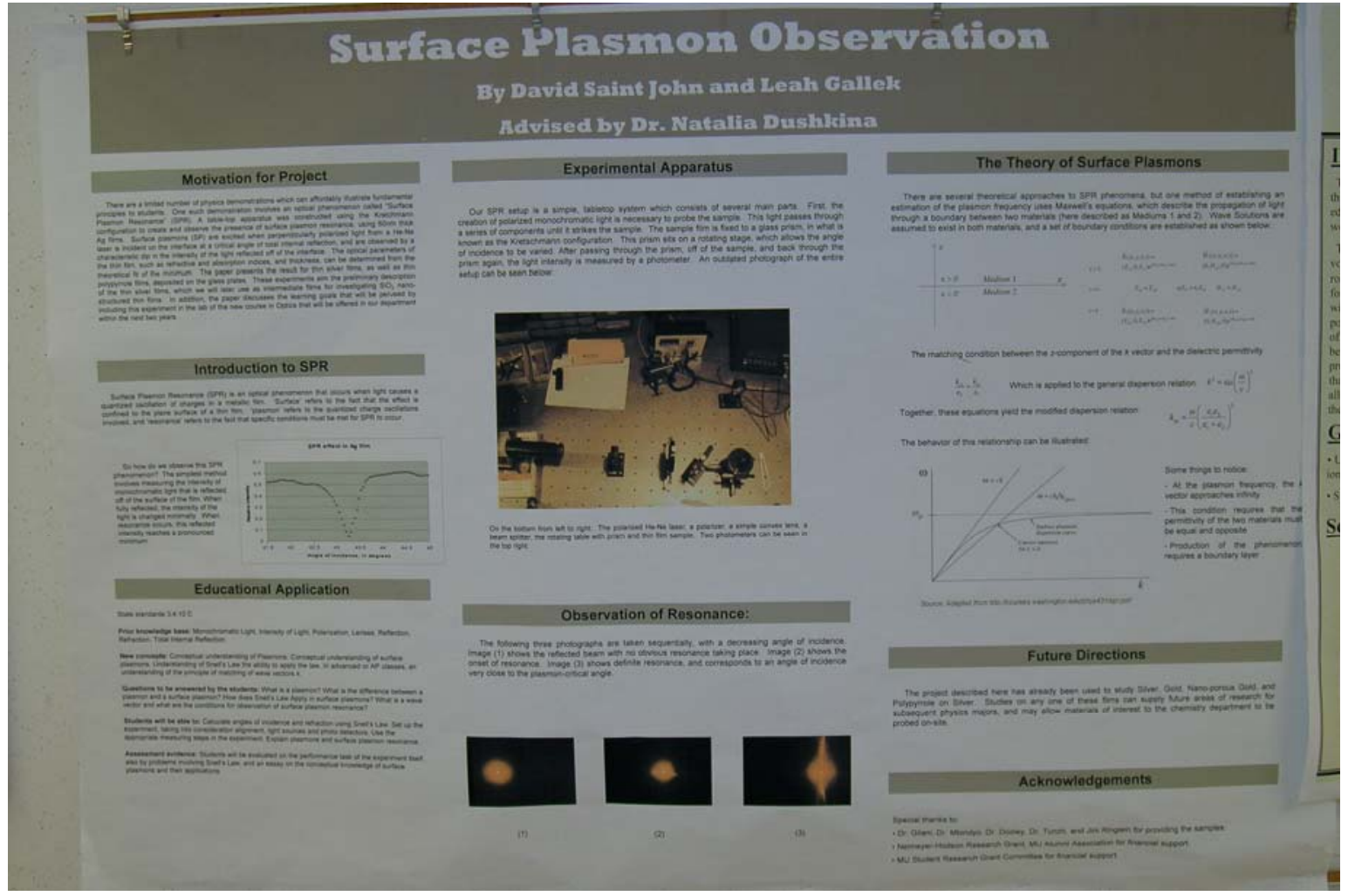

Figure 1. Undergraduate student research paper on Surface Plasmon Resonance. 


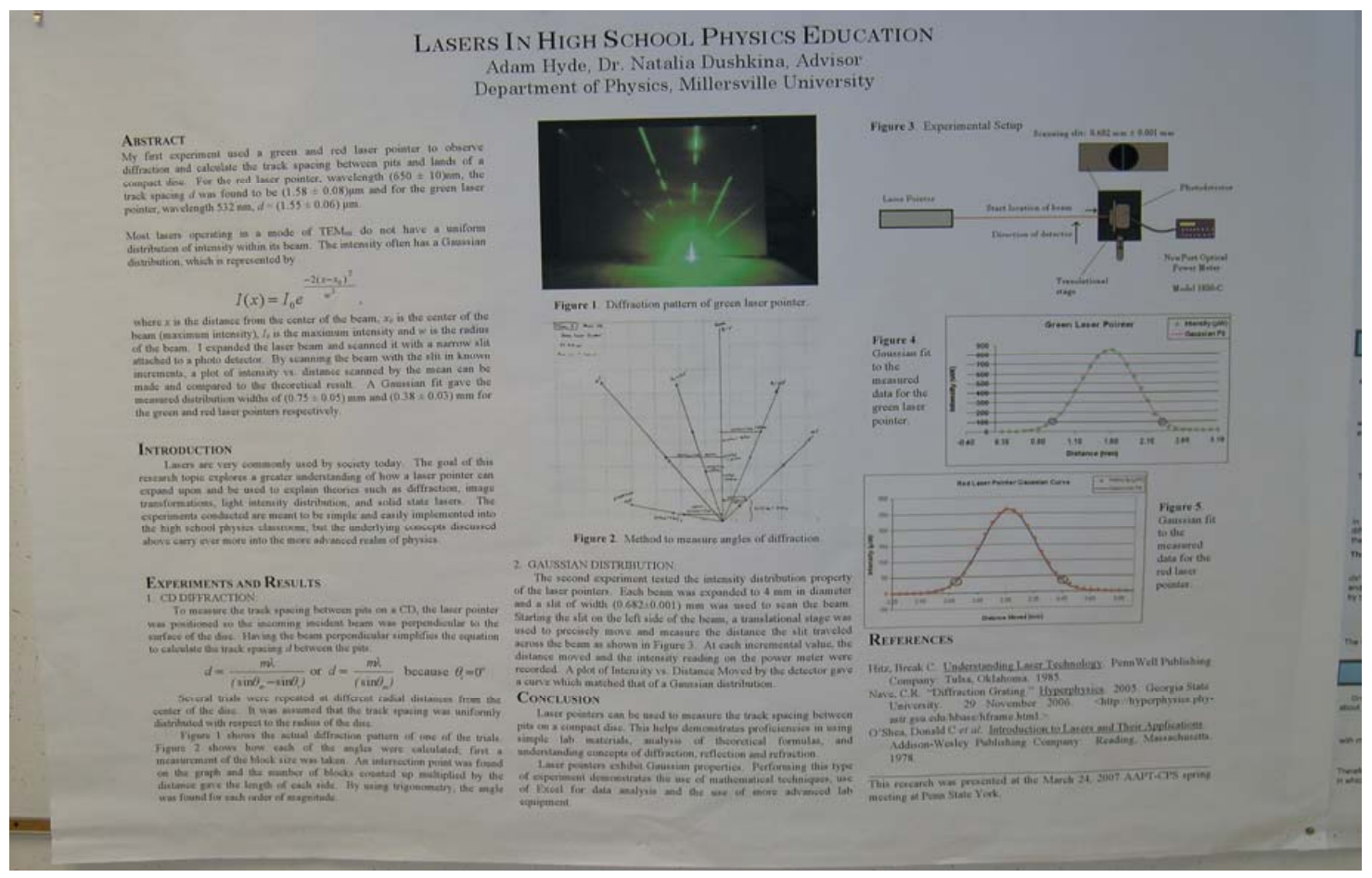

Figure 2. Student research paper on applications of laser pointers in high-school physics education.

\section{Spectral Calculations for Columnar Thin Films Deposited on Periodically Decorated Substrates}

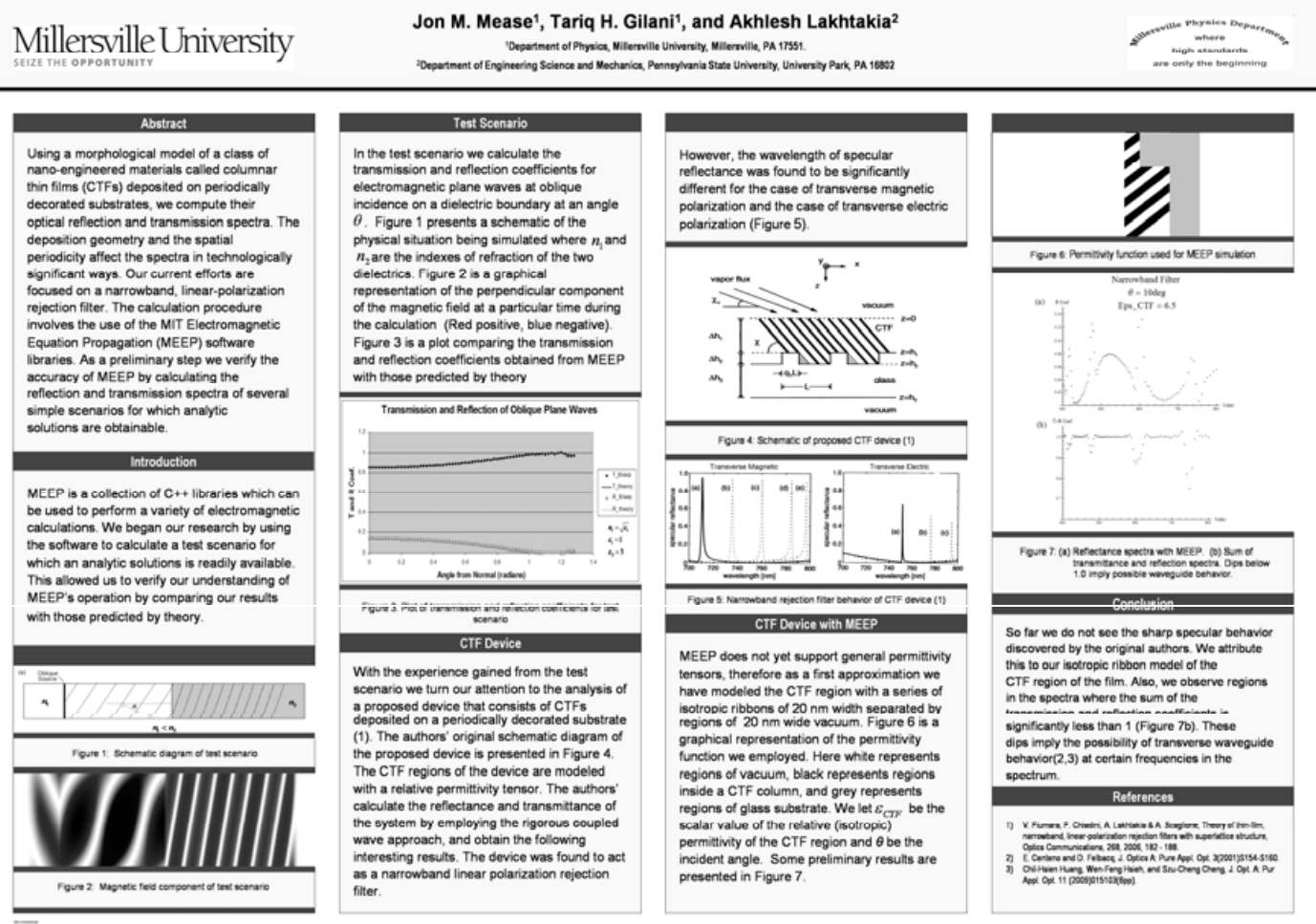

Figure 3. Student research paper on spectral calculations for columnar thin films deposited on periodically decorated substrate. 


\subsection{Lasers and their Application course}

A new 400-level course "Lasers and Their Applications" was developed by one of the authors of this paper and was offered in spring of 2009. The main objective of the course was to make students familiar with the basic principles, characteristics and some of the applications of the lasers. The students learn the principles of laser operation, the nature of most common laser systems, feedback systems, resonators, modes, line shapes, broadening mechanism, Q-switching, semiconductor lasers, gas lasers, Dye lasers and some lasers applications. This course provides the foundation for further in depth studies at graduate level in the field of lasers. The details of the course will be published somewhere else.

\subsection{Outreach}

The successful start of the optics course was reflected in the School of Science and Mathematics PHYSICS Newsletter, fall 2008. The paper includes three pictures from the class of fall 2008 on total internal reflection (Fig. 4), a lecture on interference of light (Fig. 5) and alignment of a He-Ne laser cavity (Fig. 6). The authors of the paper were interviewed by Madelyn Pennino, a journalist at Intelligencer Journal, and the new Optics course was featured in her article "MU's optics course - a study in success", Intelligencer Journal, February 2, 2008. The experiments on "Laser Construction" and "Generating Surface Plasmons" performed in the class of fall 2007 were featured at the MU Physics homepage, as the "Experiment of the month", December 2007 and April 2008, and the optical set-up of a Michelson interferometer from the class of fall 2008 is on the title page of the Physics Department brochure.

In general, most high school students receive little exposure to physics, and, consequently, to optics. As a result, few students are aware of the ample career opportunities in this field. In order to attract the student's attention to this rapidly evolving discipline, we offer annual summer workshops for high school students. The first, Color Formation, is addressed to 8-9 graders (usually students with no exposure to physics), while the second one Physical Colors targets the junior and senior students (10-12 graders) who may have had taken physics courses. These two workshops are part of the educational and research activities of the Summer Science Training Program (SSTP) held for three weeks on the MU campus for a select group of local and regional high

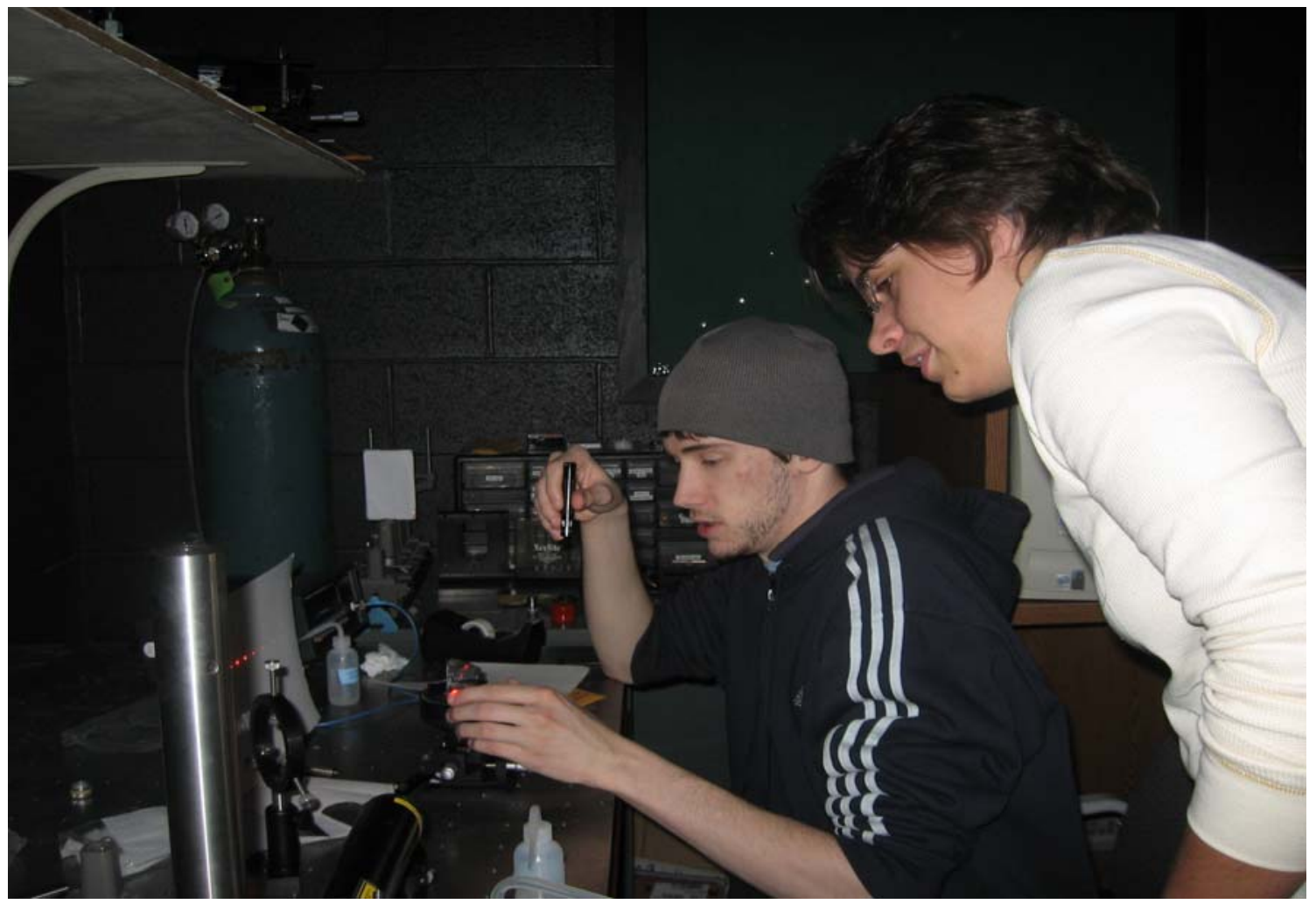

Figure 4. Project: Total Internal Reflection and Surface Plasmon Resonance. 


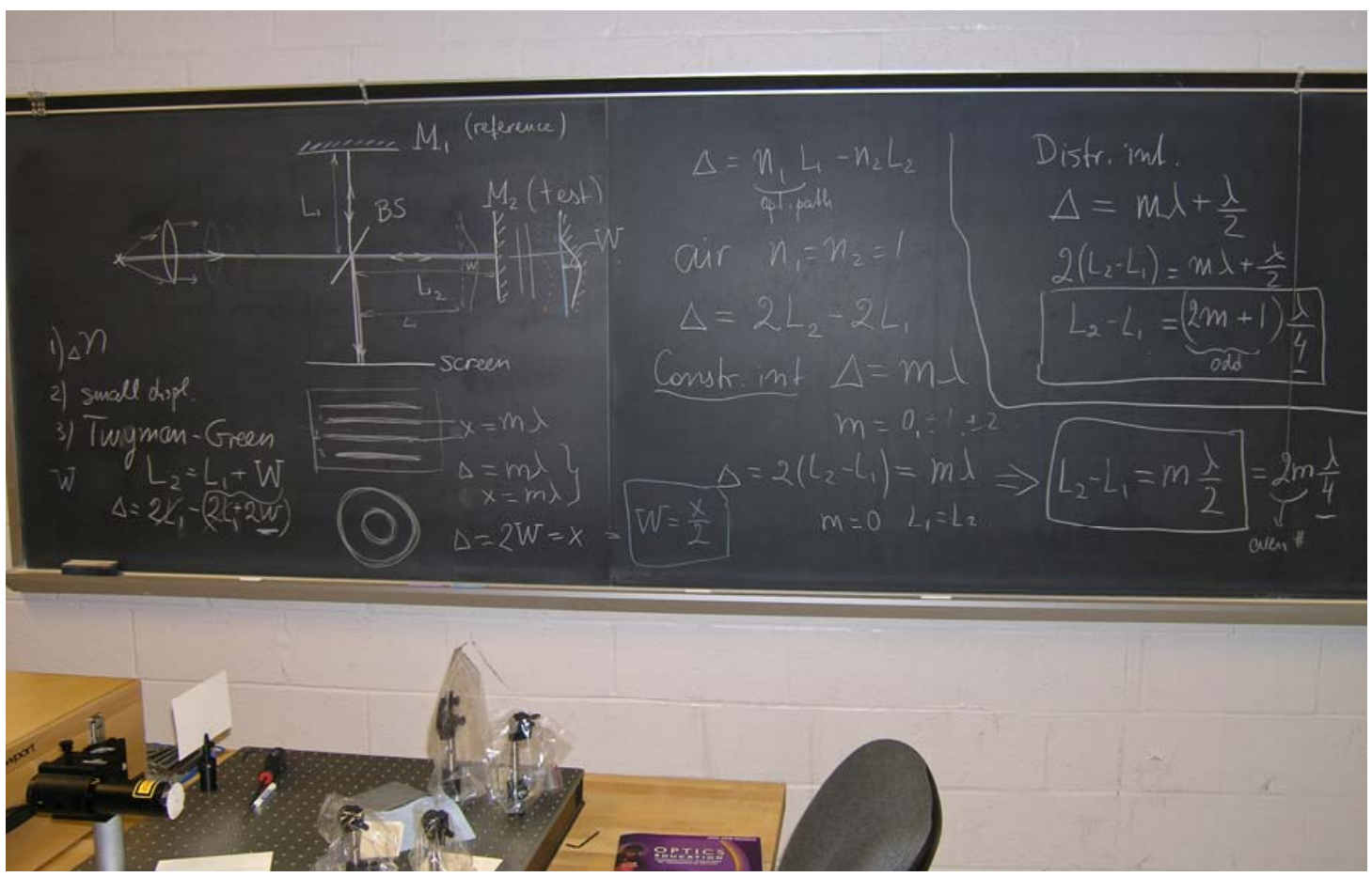

Figure 5. Lecture on interference of light.

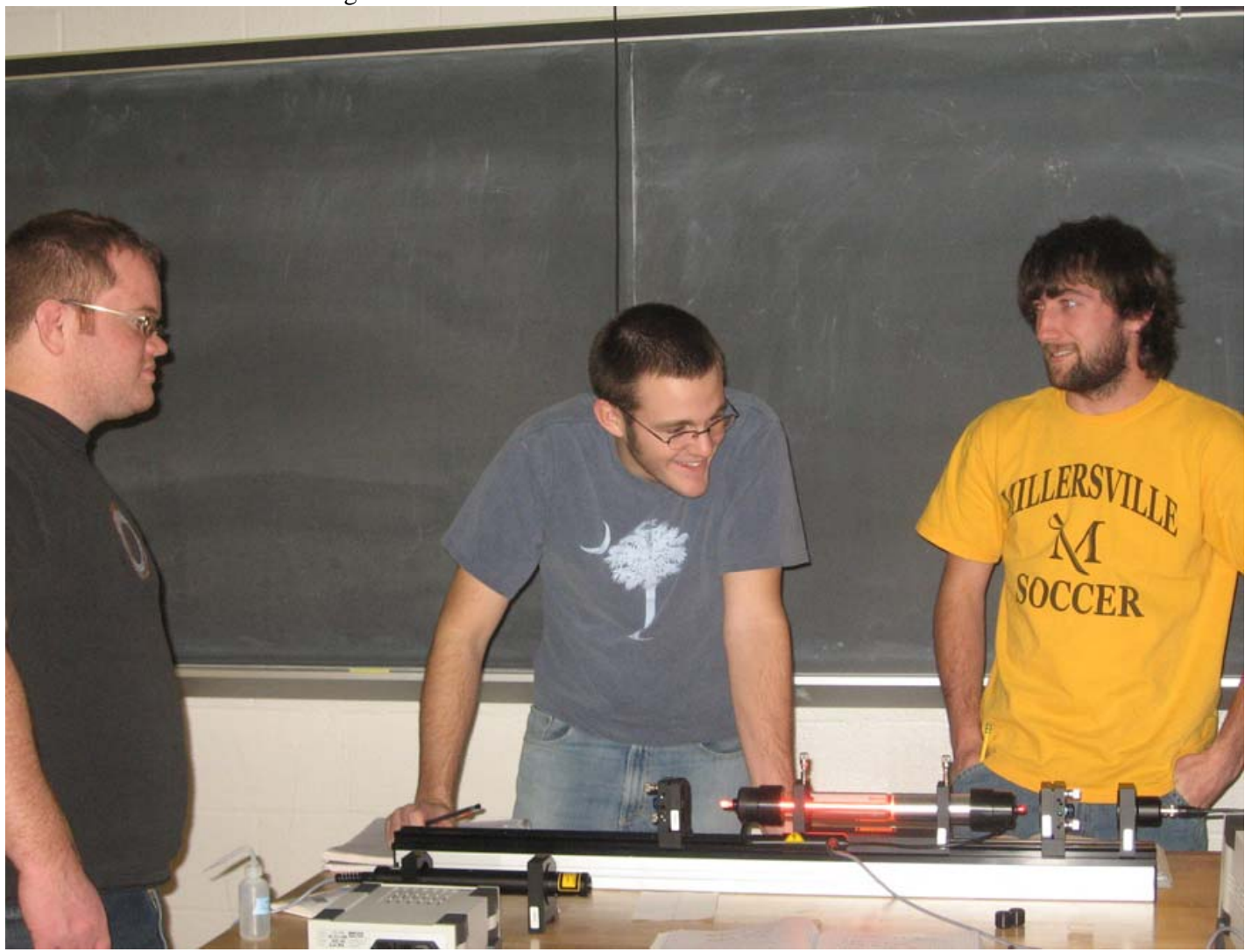

Figure 6. Project: Alignment of a He-Ne Laser.

Proc. of SPIE Vol. $9666966618-9$ 
school students. The new optics course provides new opportunities to enrich the existing workshops and to expand our offerings with a workshop suitable for high school physics teachers.

Another way to promote participation of bright students in optical programs is mentoring high school student research projects. We sustain a continuous collaboration with a physics teacher at the Lancaster Country Day School supervising his student's projects in optics and helping them to build optical experiments. We introduced the phenomena of surface plasmon resonance (SPR) to him and to one of his students and opened our lab for them to study SPR in porous gold samples [14].

\section{EVALUATION}

\subsection{Assessment of student's learning}

Student's learning and progress is assessed on a continuous base through the entire course. The continuous screening involves class and group discussions on thought-provoking questions, as the emphases are on student's misconceptions and experimental missteps. The student's preparedness and performance is reviewed, and the lab report for each lab experiment is graded on the basis of meaningful quantitative data, as well as qualitative interpretations. Three (two midterms and a final) exams are used for the lecture material. The exams include also questions on the laboratory experiments in order to assess the student's understanding of the lab procedures and data analysis. The student's individual work and self learning is assessed via the student's individual projects and PowerPoint ${ }^{\circledR}$ presentations. The presentations are evaluated based on content, oral delivery, visual aids, and relevance.

\subsection{Course evaluation}

At the end of the course, students complete a questionnaire on various aspects of the course. Students evaluate their background preparedness for the course, qualitative lap of knowledge, preliminary competency in lab techniques, the effectiveness of the lab experiments and projects, what lab experiments meet the course objectives, the effectiveness of the instructor's guidance, what should be improved in the lecture and lab portions of the course. The constructive students' suggestions are the base for changes and improvement of the course.

\section{THE IMPACT OF THE OPTICS COURSE}

\subsection{Undergraduate Research and Training in Optics}

The new optics course impacted strongly the department's advanced lab, undergraduate research and training program. A few research projects in optics were already offered to students for their two-semester senior seminar courses, PHYS 492 and PHYS 498, which are required for graduation for all physics majors. The optics teaching laboratory was incorporated also into the PHYS 451 and 452 advanced laboratories and the department's undergraduate research. Some of the research projects were already mentioned above.

\subsection{The impact on the other departments through the School of Mathematics and Science}

The new course has inspired new projects and new opportunities for collaborations, such as the collaborative project between the authors of this paper and six other faculty members from Indiana University of Pennsylvania and Penn State at State College, PA. The course has increased the interdisciplinary work and joint activities among the departments of the School of Mathematics and Science.

\subsection{The impact on the department's curriculum}

The Optics course was the basis for offering the course in lasers and their applications in spring 2010, which was already discussed in this paper. A possible advanced course in optics could deal with detailed introduction to basic optical standards and international standardization aspects of optical engineering, and laser

safety standards, which will provide insight to terminology, requirements, interfaces, test methods, and product safety, that apply to complete optical systems, devices or components. 
With an additional advanced optics course, the Department will be able to offer a new option in BA physics with optics. Therefore, the described efforts will provide new opportunities and enrichment of the already existing two cooperative programs between our Department and The Pennsylvania State University and University of Southern California.

\subsection{The impact on the community}

The optics course provides the basic resources for both research and training in modern optics. It promotes learning, teaching and training of students, faculty and K-12 teachers. Based on our experience with the course we could offer a summer training workshop for K-12 teachers in the following summers.

Our current percentage of female physics majors is typically between 10 and 20 percent. Most of our female students are enrolled in the BS in Education (Physics) program. Since optics is one of the most demonstrable parts of physics, we believe that the new optics course in combination with the BSE option will attract more female students to the field of physics and physics education.

We regularly host open house receptions for the campus community and students, parents and teachers from the local high-schools. The guests visit our optics laboratory and have the opportunity to speak with instructors and students involved in the optics course and to hear by word of mouth their experiences and future plans.

\section{CONCLUSION}

A rigorous lab based course in applied optics has been offered for the first time at MU in the fall of 2007. The course is required for BS physics majors, and is open also to all majors from the School of Mathematics and Science, who have met the prerequisite requirements. Enrollment is restricted only by prerequisites and lab equipment limitations. The primary goal of the course is to provide students with the theoretical background and hands-on experiences necessary to enable them to successfully apply optics in their respective majors. Students learn the fundamentals of applied optics through a sequence of hands-on laboratory experiments using state-ofthe-art equipment and multidisciplinary individual projects. Because of the hands-on experience requirement the enrollment is limited to maximum 12 students per semester. Initially, the optics course is offered annually. Adapting our educational efforts to the future challenges of our students, college education and training in optics became high priority for the Physics Department at MU.

\section{ACKNOWLEDGEMENTS}

We acknowledge the support of the MU Physics Department, as well as the Dean of the School of Mathematics and Science, MU, for his encouragement and the financing of this project.

\section{REFERENCES}

[1] A. M. Odlyzko, "Internet traffic growth: Sources and implications," Proc. ITCOM, SPIE (2003). Eversion at http://www.dtc.umn.edu/ odlyzko/doc/itcom.internet.growth.pdf

[2] Some of the experiments are described on the MU Physics Department's website at http://muweb.millersville.edu/ physics/

[3] R. Barat, J. Federici, A. Johnson, H. Gebel, and T. Chang, "Optical Science and Engineering Curriculum at NJIT,” Journal of Engineering Education, 575-582, (1998 Supplement).

[4] New Jersey Institute of Technology, Optical Science and Engineering (OPSE) Program,http://www.njit.edu/v2/Directory/Centers/OPSE/Welcome.html

[5] O. F. Swenson, D. A. Rogers, R. M. Patterson, A. Campiglia, "Optics for scientists and engineers," $32^{\text {nd }}$, ASEE/IEEE Frontiers in Education Conference, November 2-9, 2002, Boston, MA, IEEE Proc., S4A8-A12 (2002)

[6] F. Zhou, "Electro-Optics Program at Indiana University of Pennsylvania”, ETOP 2005, pp. 121126/416.

[7] Martin Nemko, "How to Get an Ivy League Education at a State University", Avon Books (1988).

[8] F. L. Pedrotti, L. S. Pedrotti, L. M. Pedrotti, Introduction to Optics, 3d ed., Pearson Education, (2007).

[9] D. C. O'Shea, W. R. Callen, W. T. Rhodes, Introduction to Lasers and their Applications, $2^{\text {nd }}$ ed., Addison Wesley (1978). 
[10] O’Svelto, “Principle of Lasers”, Plenum Press (1998).

[11] D. C. O’Shea, “The Elements of Modern Optical Design”, J. Wiley and Sons, New York (1985).

[12] K. D. Moller, “Optics”, University Science Books, Mill Valley, CA (1988).

[13] Projects in Optics Workbook, Newport Corp.

[14] J. Ringlein, "Secondary Teacher Interacting with Materials Professors Strikes Gold”, MRS Bulletin 32, 179 (2007). 